\title{
Ambulatory assistive devices and walking performance in patients with incomplete spinal cord injury
}

\author{
W Saensook ${ }^{1,2,3}$, S Phonthee ${ }^{1,2}$, K Srisim ${ }^{1,2}$, L Mato ${ }^{1,2}$, P Wattanapan ${ }^{2,3}$ and S Amatachaya ${ }^{1,2,4}$
}

\author{
Study design: A cross-sectional study. \\ Objectives: To primarily explore types of ambulatory assistive device (AAD) used and secondarily describe walking performance in \\ independent ambulatory patients with spinal cord injury (SCI) who walked without and with various AADs as determined using walking \\ speed and distance walked in 6 min.
}

Setting: A tertiary rehabilitation center and community hospitals, Thailand.

Methods: The data of 195 independent ambulatory patients with SCI were used to describe the use of an AAD. Among these, only 140 subjects were assessed for their walking speed and distance walked in 6 min.

Results: More than half of the subjects (64\%) walked with an AAD in which most of them used a standard walker (45\%), followed by a single-tip cane (11\%) and bilateral crutches $(8 \%)$, respectively. The walking speed and distance showed significant differences among the groups $(P<0.001)$, except those who used walker versus crutches, and those who used crutches versus cane $(P>0.05)$. Among the significant variables, types of AAD used had the greatest influence on walking speed and distance of the subjects.

Conclusion: More than half of ambulatory subjects with SCl walked with an AAD in which most of them used a standard walker. However, the non-significant differences of walking performance between the groups may suggest the heterogeneity of walking ability in subjects who used the same type of AAD. Therefore, a method to facilitate the use of an AAD with less supportive ability would increase levels of independence for the patients.

Spinal Cord (2014) 52, 216-219; doi:10.1038/sc.2013.120; published online 15 October 2013

Keywords: walking device; walker; crutches; cane; rehabilitation

\section{INTRODUCTION}

Most patients with motor incomplete spinal cord injury retain or regain ambulatory ability after rehabilitation. ${ }^{1}$ However, the quality and ability of ambulation may be affected by sensorimotor dysfunctions such as spasticity, diminished or absent lower extremity muscle strength and difficulty with timing and sequencing of muscle activation. $^{2}$ Therefore, ambulatory ability of the patients is likely to be limited to a certain location such as within the house or over a short distance and required lower-extremity braces or an ambulatory assistive device (AAD), that is, cane, crutches or walker. ${ }^{3,4}$

An AAD is commonly used to reduce lower-limb loading, which helps to alleviate joint pain or compensate for the weakness of lower extremity muscles. ${ }^{4,5}$ In addition, an AAD provides mechanical advantages, and increases the body base of support, which improves balance control and levels of independence of the patient. ${ }^{5,6}$ Therefore, using an AAD creates an opportunity to activate the neuromuscular functions below the level of the lesion via task-specific experience of walking training. ${ }^{7}$ However, walking with an AAD increases attention and metabolic demands depending on the type and supportive ability of the AAD. ${ }^{3,5,8}$ This affects walking speed and distance, which are important contributors for ability to perform daily activities and participate in a community. ${ }^{3,9}$ Zorner et al. ${ }^{9}$ report that individuals with SCI need a walking speed of at least $0.6 \mathrm{~m} \mathrm{~s}^{-1}$ to safely cross a street. The researchers also used this speed to categorize patients with SCI into functional and non-functional ambulators. Lapointe et al. ${ }^{6}$ utilized the distance of $342 \mathrm{~m}$ to determine the functional distance required for community ambulation. Furthermore, Du et al. ${ }^{10}$ applied the distance of $350 \mathrm{~m}$ as an adequate level for functional endurance.

Nowadays, there is a trend toward a decreased length of rehabilitation for patients with SCI. ${ }^{11}$ It is likely that patients cannot achieve an optimal level of ability at the time of discharge, and this may increase the need of an AAD for daily activities. Although an AAD has several advantages, long-lasting use of an inappropriate $\mathrm{AAD}$ can attribute negative impact for the patients. ${ }^{3,5,8}$ To the researcher's knowledge, there is little evidence for the prevalence of AAD used in ambulatory patients with SCI. In addition, data on walking performance as determined using walking speed and distance for those who use various types of $\mathrm{AAD}$ may provide clear evidence on the ability of these patients to conduct daily activities. Therefore, this study primarily explored types of AAD used and secondarily assessed walking performance of independent ambulatory patients with SCI, as measured using the 10-Meter Walk Test (10MWT) and the 6-Minute Walk Test (6 MinWT).

${ }^{1}$ School of Physical Therapy, Faculty of Associated Medical Sciences, Khon Kaen University, Khon Kaen, Thailand; ${ }^{2}$ Improvement of Physical Performance and Quality of Life (IPQ) Research Group, Khon Kaen University, Khon Kaen, Thailand; ${ }^{3}$ Department of Rehabilitation Medicine, Faculty of Medicine, Khon Kaen University, Khon Kaen, Thailand and ${ }^{4}$ Back, Neck and Other Joint Pain (BNOJP) Research Group, Khon Kaen University, Khon Kaen, Thailand

Correspondence: Dr S Amatachaya, School of Physical Therapy, Faculty of Associated Medical Sciences, Khon Kaen University, Mittraphap Highway, Khon Kaen, 40002, Moung, Thailand.

E-mail: samata@kku.ac.th

Received 2 July 2013; revised 22 August 2013; accepted 11 September 2013; published online 15 October 2013 


\section{MATERIALS AND METHODS}

\section{Subjects}

The data were collected from independent ambulatory patients with SCI (American Spinal Injury Association [ASIA] Impairment Scale [AIS] class C and D) who visited an outpatient and inpatient department in a tertiary rehabilitation center and community hospitals in Thailand during 2011-2013. The inclusion criteria were the ability to walk independently with and without an $\mathrm{AAD}$ over at least $17 \mathrm{~m}$ continuously (Functional Independence Measure Locomotor scores $\geqslant 5$ ). ${ }^{12}$ Any patients with signs and symptoms that might affect the outcomes were excluded from participation in the study, that is, leg length discrepancy and pain in the musculoskeletal system with a pain score of more than 5 out of 10 on a visual analog scale. We certify that all applicable institutional and governmental regulations concerning the ethical use of human volunteers were followed during the course of this research.

\section{Research protocol}

Subjects were interviewed and assessed for their baseline demographics (i.e., gender, age, weight, height and body mass index), SCI characteristics (including causes, level, severity and post onset of SCI) and types of customary AAD used according to their own determination. Then they were assessed for their walking performance using the 10MWT followed by the $6 \mathrm{MinWT}$ in order to reduce effects of fatigue that might occur due to the high demand of the $6 \mathrm{MinWT}$ on the outcome of the 10MWT. Details of the tests are as follows.

10-Meter Walk Test. The 10MWT measures ambulatory status of the subjects in terms of walking speed. Subjects walked at a comfortable pace with or without an $\mathrm{AAD}$ according to their usual walking along a $10 \mathrm{~m}$ walkway. In order to minimize acceleration and deceleration effects, the test recorded the time required over the middle $4 \mathrm{~m}$ of the walkway and the average findings over the 3 trials were used for data analysis. ${ }^{7}, 13$

6-Minute Walk Test. Subjects were required to walk along a rectangular walkway with or without a customary AAD for as long as possible in $6 \mathrm{~min}$. During the test, subjects were allowed to rest as needed, without stopping the timer, and continued walking as soon as they could. Every minute during the test, subjects were informed about the time left and offered encouragement. Then the distance covered after 6 min was recorded. ${ }^{14}$

During the tests, subjects wore a lightweight safety belt with an assessor walking alongside the subjects to ensure their safety and the accuracy of the tests. Subjects were able to take a period of rest between the tests and the trials, as required.

\section{Statistical analyses}

Descriptive statistics were used to explain baseline demographics, SCI characteristics and findings of the study. The different findings among the groups were compared using the one-way analysis of variance (ANOVA) and the $\chi^{2}$ test for the continuous and categorical data, respectively. Then the posthoc analysis (Scheffe's test) was utilized to identify the differences of continuous data for every pairwise condition. Furthermore, the regression analysis was used to determine effects of baseline characteristics on the outcomes of walking tests. The level of significant difference was set at $P<0.05$.

\section{RESULTS}

One hundred and ninety-five independent ambulatory subjects with SCI participated in the study. Among these, more than half of the subjects used an $\operatorname{AAD}(n=124,64 \%)$ in which most of them walked with a standard walker, followed by a single-tip cane and bilateral crutches (Figure 1). Of these, one subject who walked with a standard walker also used a plastic ankle foot orthosis.

Because the walking tests were introduced after starting the study, only 140 subjects were involved in the 10MWT and 6MinWT. Of these, 59 subjects used a standard walker, 12 subjects walked with crutches (forearm crutches $[n=1]$ and axillary crutches $[n=11]$ ),

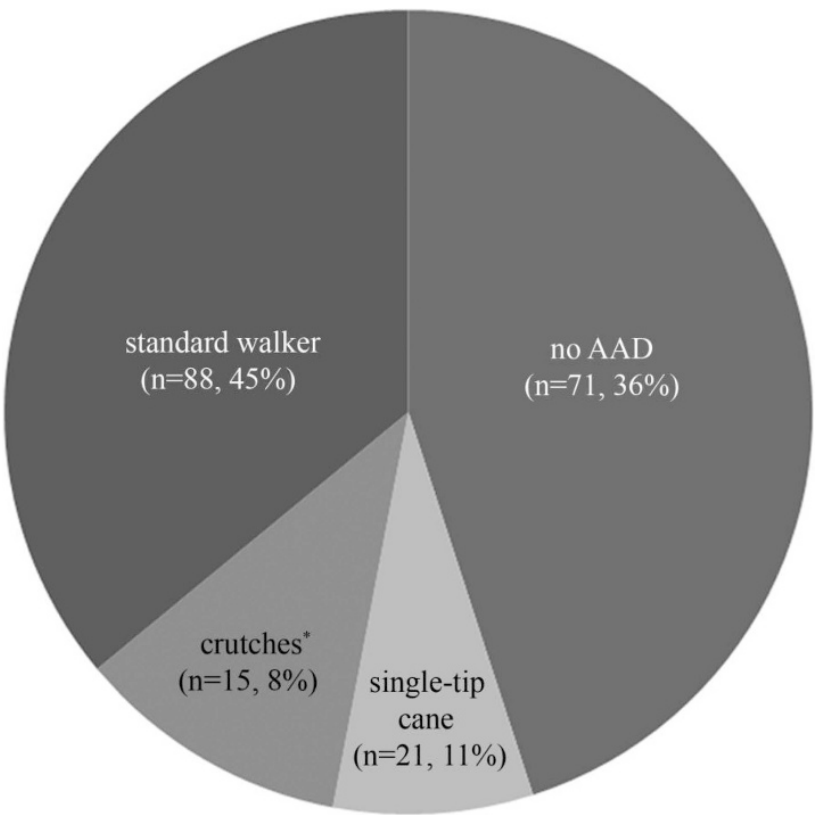

Figure 1 The types of ambulatory assistive device (AAD) used in independent ambulatory subjects with spinal cord injury $(n=195)$. Note: ${ }^{*} 1$ subject used forearm crutches and 14 subjects walked with axillary crutches.

Table 1 Baseline demographics and spinal cord injury characteristics of the subjects $(n=140)$

\begin{tabular}{|c|c|c|c|c|c|}
\hline \multirow[t]{2}{*}{ Variable } & \multicolumn{4}{|c|}{ Groups of subjects } & \multirow[t]{2}{*}{ P-value } \\
\hline & $\begin{array}{l}\text { Walker } \\
(\mathrm{n}=59)\end{array}$ & $\begin{array}{l}\text { Crutches } \\
(\mathrm{n}=12)\end{array}$ & $\begin{array}{c}\text { Cane } \\
(\mathrm{n}=16)\end{array}$ & $\begin{array}{l}\text { No } A A D \\
(\mathrm{n}=53)\end{array}$ & \\
\hline Age $(y r)^{a}$ & $50.5 \pm 15.5$ & $46.2 \pm 14.7$ & $7 \quad 59.0 \pm 10.7$ & $50.8 \pm 12.1$ & 0.072 \\
\hline Weight (kg)a & $61.5 \pm 11.4$ & $57.9 \pm 8.5$ & $59.7 \pm 7.5$ & $60.6 \pm 12.3$ & 0.770 \\
\hline Height $(m)^{a}$ & $163.7 \pm 6.7$ & $164.3 \pm 7.8$ & $157.4 \pm 7.1$ & $164.2 \pm 7.5$ & $0.010^{b}$ \\
\hline $\begin{array}{l}\text { Body mass index } \\
\left(\mathrm{kg} \mathrm{m}^{-2}\right)^{a}\end{array}$ & $22.9 \pm 4.1$ & $21.5 \pm 2.9$ & $24.2 \pm 3.3$ & $22.4 \pm 3.9$ & 0.252 \\
\hline $\begin{array}{l}\text { Post-injury time } \\
\text { (months) }\end{array}$ & $47.1 \pm 46.2$ & $58.3 \pm 69.7$ & $763.1 \pm 44.3$ & $35.1 \pm 55.8$ & 0.591 \\
\hline $\begin{array}{l}\text { Gender: Male } \\
{[n(\%)]^{c}}\end{array}$ & $41(69)$ & $11(92)$ & $6(37)$ & $40(75)$ & $0.009^{b}$ \\
\hline $\begin{array}{l}\text { Cause of injury: } \\
\text { Traumatic }[n(\%)]^{c}\end{array}$ & $21(36)$ & $8(67)$ & $4(25)$ & $20(38)$ & 0.152 \\
\hline $\begin{array}{l}\text { Severity of injury: } \\
\text { AIS C }[n(\%)]^{c}\end{array}$ & $32(54)$ & $7(58)$ & $5(31)$ & $5(9)$ & $0.000^{b}$ \\
\hline $\begin{array}{l}\text { Level of injury: } \\
\text { Incomplete para- } \\
\text { plegia }[n(\%)]^{c}\end{array}$ & 41 (69) & $10(83)$ & $14(88)$ & $37(70)$ & 0.394 \\
\hline Stage of injury: & $40(67)$ & $9(75)$ & $15(94)$ & 37 (69) & 0.059 \\
\hline
\end{tabular}

Chronic $[\mathrm{n}(\%)]^{\mathrm{c}}$

Abbreviations: AAD, ambulatory assistive device; AIS, American Spinal Injury Association (ASIA) Impairment Scale; SCI, spinal cord injury.

aThe data are presented using mean \pm s.d., and the differences among the groups were analyzed using the one-way ANOVA.

bIndicates significant differences among the groups.

CThese variables were categorized according to the following criteria; gender: male/female, cause of injury: traumatic/non-traumatic, severity of injury: AIS C/D, level of injury: incomplete paraplegia/incomplete tetraplegia, stage of injury: subacute/chronic. The comparisons among the groups were executed using the chi-square test. 

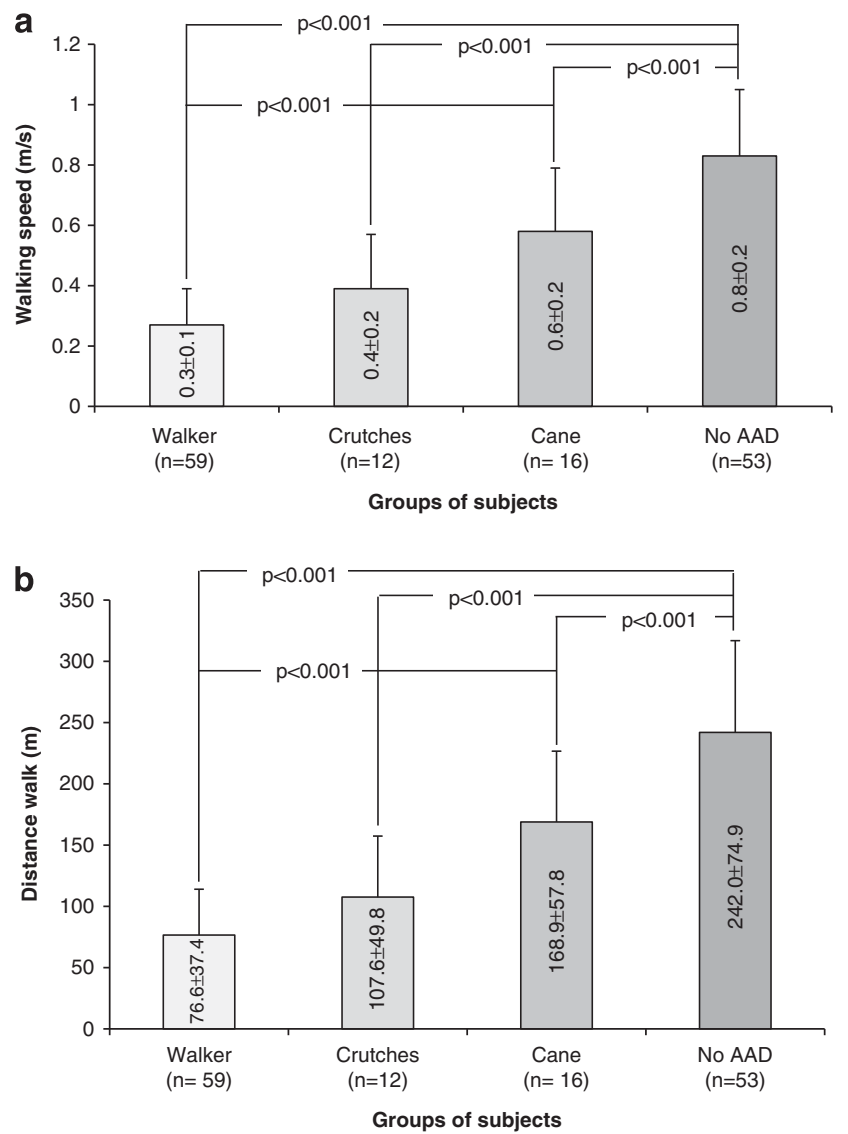

Table 2 Predictive equations for the walking tests using data from the significant variables

\begin{tabular}{|c|c|c|c|}
\hline $\begin{array}{l}\text { Functional } \\
\text { tests }\end{array}$ & Predictive equations & $\begin{array}{c}\text { Adjusted } \\
\mathrm{R}^{2}\end{array}$ & $\begin{array}{l}\text { Comparison } \\
\text { groups }\end{array}$ \\
\hline \multirow[t]{4}{*}{$\begin{array}{l}\text { 10-Meter Walk } \\
\text { Test (10 MWT) }\end{array}$} & $10 \mathrm{MWT}=1.6-0.5(\mathrm{AAD})+0.1(\mathrm{AIS})$ & 0.71 & $\begin{array}{l}\text { Walker }{ }^{2}-\text { no } \\
\text { AAD }\end{array}$ \\
\hline & $10 \mathrm{MWT}=1.6-0.4(\mathrm{AAD})+0.2(\mathrm{AIS})$ & 0.43 & $\begin{array}{l}\text { Crutches }^{\mathrm{a}}- \\
\text { no } A A D\end{array}$ \\
\hline & $10 \mathrm{MWT}=1.3-0.3(\mathrm{AAD})+0.02(\mathrm{AIS})$ & 0.22 & $\begin{array}{l}\text { Cane }^{\mathrm{a}}-\text { no } \\
\text { AAD }\end{array}$ \\
\hline & $\begin{array}{l}10 \mathrm{MWT}=1.8-0.4(\mathrm{AAD})+0.2(\mathrm{AIS}) \\
-0.007 \text { (Height) }\end{array}$ & 0.61 & $\begin{array}{l}A^{A} D^{a}-\text { no } \\
A A D\end{array}$ \\
\hline 6-Minute Walk & $6 \mathrm{MinWT}=499.8-143.5(\mathrm{AAD})$ & 0.71 & Walkera-no \\
\hline \multirow[t]{4}{*}{ Test (6 MinWT) } & $+46.1(\mathrm{AIS})+28(\text { Gender })^{\mathrm{b}}$ & & $A A D$ \\
\hline & $\begin{array}{l}6 \mathrm{MinWT}=526.3- \\
110.7(\mathrm{AAD})+60.9(\mathrm{AIS})\end{array}$ & 0.44 & $\begin{array}{l}\text { Crutches }^{\mathrm{a}}- \\
\text { no } A A D\end{array}$ \\
\hline & $\begin{array}{l}6 \mathrm{MinWT}=611.8-72.7(\mathrm{AAD}) \\
+55.7(\text { AIS)-2.6(Height) }\end{array}$ & 0.23 & $\begin{array}{l}\text { Cane }^{\mathrm{a}}-\text { no } \\
\text { AAD }\end{array}$ \\
\hline & $\begin{array}{l}6 \text { MinWT }=582-126.2(\text { AAD }) \\
+46.3(\text { AIS })-2.4 \text { (Height) }\end{array}$ & 0.61 & $\begin{array}{l}\text { AAD }^{a}-\text { no } \\
\text { AAD }\end{array}$ \\
\hline
\end{tabular}

Abbreviations: AAD, ambulatory assistive device; AIS, American Spinal Injury Association (ASIA) Impairment Scale.

AIS D was set as 1 and AIS $C$ was set as 0 .

aThe value was set as 1 and the no AAD group was set as 0 .

bMale was set as 1 and female was set as 0 .

Figure 2 Walking ability of the subjects as determined using. (a) The 10-Meter Walk Test. (b) The 6-Minute Walk Test.

16 subjects used a single-tip cane and the rest did not use an AAD. Table 1 presents baseline demographics and SCI characteristics of these subjects in which there were no significant differences among the groups, except height, gender and severity of injury. The data of walking performance demonstrated that walking speed and distance of subjects who did not use an AAD were significantly better than those who walked with an AAD $(P<0.001$, Figure 2$)$. Moreover, the data of subjects who walked with a cane were significantly better than those who used a walker $(P<0.001)$. However, there were no significant differences between the findings of those who used a walker versus crutches, and those who walked with crutches versus a cane $(P>0.05$, Figure 2). The regression analysis indicated that the types of AAD used, severity of injury, gender and height were the significant variables for the performance of 10MWT and 6 MinWT in which their explanatory ability ranged from $22-71 \%$ (Table 2 ).

\section{DISCUSSION}

Currently, only a few studies reported data on AAD used in subjects with SCI. To the researchers' knowledge, there was only a study of Brotherton et al. ${ }^{3}$ who collected the data on AAD used and distance walked in ambulatory subjects with SCI using a self-report questionnaire. The researchers found that approximately two-thirds of subjects with SCI (66\%) used an AAD but the types of AAD used $(28 \% \text { used a walker, } 20 \% \text { walked with crutches and } 30 \% \text { used a cane })^{3}$ were not obviously different as those showed in the present study (Figure 1). However, the use of an AAD in ambulatory subjects with
SCI, as found in the current study and a previous report, ${ }^{3}$ was clearly higher than that reported in other groups of subjects such as stroke $(36 \%)$ and elderly $(15 \%){ }^{15,16}$

Walking speed and distance are important predictors for community ambulation. ${ }^{3,6,9}$ Walking speed is considered as a surrogate for the overall quality of gait and motor function. ${ }^{17}$ It is a vital variable to indicate ability to respond to community challenges within the allowance of time limit, that is, crossing streets with traffic lights. ${ }^{6,9}$ The longest distance walked in $6 \mathrm{~min}$ indicates the global and integrated responses of the pulmonary, cardiovascular and muscular systems, and thus reflects individuals' functional status to conduct daily activities. ${ }^{18}$ Findings of the present study (Figure $2 \mathrm{~b}$ ) demonstrated that subjects who walked with an $\mathrm{AAD}$ had a walking speed clearly less than the levels for functional ambulation $\left(0.6 \mathrm{~m} \mathrm{~s}^{-1}\right)$. In addition, the distance walked by the subjects, even those who walked without an AAD (Figure 2), was obviously shorter than that needed as an adequate level for functional endurance $(350 \mathrm{~m})^{10}$ and that found in Thai female elderly aged more than 80 years. ${ }^{19}$ The findings may suggest that ambulatory subjects with SCI may have a problem for community participation, even those who did not use an AAD.

The regression analysis was performed in order to reflect effects of the significant variables on the reduction of walking performance as compared with the no AAD condition. The findings indicated that types of $\mathrm{AAD}$ used, severity of SCI, gender and height contributed significantly on walking performance of the subjects (Table 2). Among these variables, types of AAD used, particularly a standard walker, attributed the greatest influence on speed and distance walked of the subjects (Table 2). Smidt and Mommons ${ }^{20}$ report that the complexity of the sequencing and timing of floor contact is increased according to the number of legs of the AAD. Moreover, using an AAD with more supportive ability or number of contact points increases attention and metabolic demands, which could reduce walking speed and distance walked in 6 min. ${ }^{5,8}$ Therefore, the researchers hypothesized that there would be significant differences in walking 
speed and distance among subjects who used different types of AAD. Surprisingly, there were no significant differences in the 10MWT and 6 MinWT between subjects who walked with a standard walker versus crutches, and between those who used crutches versus a single-tip cane $(P>0.05$, Figure 2). A plausible explanation for the nonsignificant differences may be that the subjects were arranged into the groups according to their own determination (usual walking). Therefore, subjects who used the same type of AAD may have various levels of ability in which some subjects may be able to advance the type of $\mathrm{AAD}$ used but they did not. As a result, there were a high number of subjects who used a standard walker (45\%; Figure 1) in which some of them might be able to advance their ability to walk with crutches. Similarly, the researchers also believed that some subjects who walked with crutches might be able to walk with a single-tip cane but they did not change the type of AAD used. In fact, using an AAD with less supportive ability would be less cumbersome, allow less appearance of disability, minimize abnormal walking manner and promote walking speed that would increase levels of independence for the patients. ${ }^{5}$ The findings may suggest the importance of a monitoring method to facilitate the use of an appropriate $\mathrm{AAD}$ for ambulatory patients with SCI.

Apart from types of AAD used, severity of SCI, gender and height also had significant influence on the walking performance (Table 2). More than half of the subjects who used an AAD with more supportive ability, that is, a standard walker and crutches, had an AIS C (Table 1), which inferred greater degree of sensorimotor deterioration than those who used a single-tip cane or no AAD. Having a high severity of the lesion had negative impact on walking ability of the subjects, and thus they walked at a slow speed and could cover a short distance in $6 \mathrm{~min}$. Moreover, most of the subjects who used a single-tip cane were females, with an average height significantly less than those in the other groups. Such characteristics contribute crucial effects on biomechanical aspects while walking that can reduce walking speed and distance covered of the subjects. ${ }^{21-23}$

Findings of this study offer data on AAD used, walking speed and distance of ambulatory subjects with SCI. Nevertheless, some limitations must be kept in mind when interpreting the findings. First, the types of $\mathrm{AAD}$ used were based on self-determination by the subjects, not the highest level of ability, in order to represent their usual requirements. However, this preference may change over time since some subjects were at a subacute stage of SCI $(n=55)$. Second, the walking tests were introduced after starting the study. Thus the data on types of AAD used were reported for total number of subjects $(n=195)$ but the data of the 10MWT and 6MinWT were derived from 144 subjects. Nonetheless, the types of AAD used in these subjects also had similar proportion as the whole samples. Lastly, among subjects who were involved in the walking tests, there were only a few number of subjects who used crutches $(n=12)$ and canes $(n=16)$, which may affect the strength and explanatory ability of the findings.

\section{DATA ARCHIVING}

There were no data to deposit.

\section{CONFLICT OF INTEREST}

The authors declare no conflict of interest.

\section{ACKNOWLEDGEMENTS}

This study was supported by funding from the Improvement of Physical Performance and Quality of Life (IPQ) research groups and Khon Kaen University, Thailand. The researchers thank Mr. Ian Thomas for his help in preparing the manuscript.

Funding support: This study received funding support from Khon Kaen University, Khon Kaen, Thailand.

1 Burns SP, Golding DG, Rolle WA Jr., Graziani V, Ditunno JF. Recovery of ambulation in motor-incomplete tetraplegia. Arch Phys Med Rehabil 1997; 78: 1169-1172.

2 Scivoletto G, Romanelli A, Mariotti A, Marinucci D, Tamburella F, Mammone A et al. Clinical factors that affect walking level and performance in chronic spinal cord lesion patients. Spine (Phila Pa 1976) 2008; 33: 259-264.

3 Brotherton SS, Saunders LL, Krause JS, Morrisette DC. Association between reliance on devices and people for walking and ability to walk community distances among persons with spinal cord injury. Spinal cord 2012; 35: 156-161.

4 Haubert LL, Gutierrez DD, Newsam CJ, Gronley JK, Mulroy SJ, Perry J. A comparison of shoulder joint forces during ambulation with crutches versus a walker in persons with incomplete spinal cord injury. Arch Phys Med Rehabil 2006; 87: 63-70.

5 Bateni H, Maki BE. Assistive devices for balance and mobility: benefits, demands, and adverse consequences. Arch Phys Med Rehabil 2005; 86: 134-145.

6 Lapointe R, Lajoie Y, Serresse O, Barbeau H. Functional community ambulation requirements in incomplete spinal cord injured subjects. Spinal cord 2001; 39: 327-335.

7 Saensook W, Poncumhak P, Saengsuwan J, Mato L, Kamruecha W, Amatachaya S. Discriminative ability of the three functional tests in independent ambulatory patients with spinal cord injury who walked with and without ambulatory assistive devices. J Spinal cord Med 2013; doi:10.1179/2045772313Y.0000000139.

8 Ulkar B, Yavuzer G, Guner R, Ergin S. Energy expenditure of the paraplegic gait: comparison between different walking aids and normal subjects. Int J Rehabil Res 2003; 26: 213-217.

9 Zörner B, Dietz V, Curt A. Clinical algorithm for predicting walking capacity based on the ASIA motor score in acute SCI. Paper presented at Combined ASIA/ISCOS Meeting: Boston, MA, 2006

10 Du H, Newton PJ, Salamonson Y, Carrieri-Kohlman VL, Davidson PM. A review of the six-minute walk test: its implication as a self-administered assessment tool. Eur $\mathrm{J}$ Cardiovasc Nurs 2009; 8: 2-8.

11 Cardenas DD, Hoffman JM, Kirshblum S, McKinley W. Etiology and incidence of rehospitalization after traumatic spinal cord injury: a multicenter analysis. Arch Phys Med Rehabil 2004; 85: 1757-1763.

12 Functional Independence Measure. Guide for the Uniform Data Set for Medical Rehabilitation (Adult FIM), version 4.0 State University of New York at Buffalo: Buffalo, NY, 1993.

13 Poncumhak P, Saengsuwan J, Kamruecha W, Amatachaya S. Reliability and validity of three functional tests in ambulatory patients with spinal cord injury. Spinal cord 2013; 51: 214-217.

14 Phonthee S, Saengsuwan J, Siritaratiwat W, Amatachaya S. Incidence and Factors Associated with Falls in Independent Ambulatory Individuals with Spinal Cord Injury: A 6-Month Prospective Study. Phys Ther 2013; 93: 1061-1072.

15 Jutai J, Coulson S, Teasell R, Bayley M, Garland J, Mayo N et al. Mobility assistive device utilization in a prospective study of patients with first-ever stroke. Arch Phys Med Rehabil 2007; 88: 1268-1275.

16 Bradley SM, Hernandez CR. Geriatric assistive devices. Am Fam Physician. 2011; 84: 405-411.

17 Jackson AB, Carnel CT, Ditunno JF, Read MS, Boninger ML, Schmeler MR et al. Outcome measures for gait and ambulation in the spinal cord injury population. Spinal cord 2008; 31: 487-499.

18 van Hedel HJ, Wirz M, Dietz V. Standardized assessment of walking capacity after spinal cord injury: the European network approach. Neurol Res 2008; 30: 61-73.

19 Thaweewannakij T, Wilaichit S, Chuchot R, Yuenyong Y, Saengsuwan J, Siritaratiwat W et al. Reference Values of Physical Performance in Well-Functioning, CommunityDwelling Thai Elderly People. Phys Ther 2013; 93: 1312-1320.

20 Smidt GL, Mommens MA. System of reporting and comparing influence of ambulatory aids on gait. Phys Ther 1980; 60: 551-558.

21 Pierrynowski MR, Galea V. Enhancing the ability of gait analyses to differentiate between groups: scaling gait data to body size. Gait Posture 2001; 13: 193-201.

22 Bohannon RW. Comfortable and maximum walking speed of adults aged 20-79 years: reference values and determinants. Age Ageing 1997; 26: 15-19.

23 Troosters T, Gosselink R, Decramer M. Six minute walking distance in healthy elderly subjects. Eur Respir J 1999; 14: 270-274. 